\title{
14. On participatory politics as a game changer and the politics of participation
}

\author{
Mercedes Bunz
}

\begin{abstract}
In this chapter, the revolutionary impact of digital technology on society is unpacked and critically assessed. Bunz asks how digital media can facilitate the increased participation of citizens, but can at the same time be used as a means for diffusion that is far less radical in its political outcomes. The idea of playfully 'hacking politics' may help to turn political problems into challenges that can be resolved through public participation, but advocating participation can just as easily change into the contracting out of state responsibilities onto citizens. As is argued in this chapter, citizens' participation does not necessarily allow for radical transformation and often does not offer enough tension and discussion to kickstart societal changes.
\end{abstract}

Keywords: Citizens' participation, hacking, politics, digital media, political gestures

"Forms of organization are inseparable from technical gestures": this proposition by Bruno Latour $(1999,210)$ was written right at the time when the internet was about to become a mass medium. As digitalization spread, a new technical gesture was on the rise (Bunz 2014, 55-59). The aim of my contribution is to follow Latour's proposition and explore it with regards to a specific type of organization: the field of politics. For this, I plan to take a general look at the effects of the technical gesture of digitalization commonly identified as "decentralization" or "fragmentation" (Castells 1996; Galloway 2004, 46; Hayles 2009, 68; Lovink 2012; Bruns et al. 2015).

Glas, R., S. Lammes, M. de Lange, J. Raessens, and I. de Vries, eds. 2019. The Playful Citizen. Civic Engagement in a Mediatized Culture. Amsterdam: Amsterdam University Press. DOI: $10.5117 / 9789462984523 / \mathrm{CH} 14$ 
Being at times discussed as promising models of anti-capitalism (Srnicek and Williams 2015; Scholz and Schneider 2017), I will specifically describe new forms of participatory politics to analyze how they have influenced a shift in the concept of the political. After some introductory remarks about the relation of organization and technology, my contribution will look at three examples that put new forms of participatory organization into play and will explain why this can be conceived as the gamification of politics (e.g. Deterding et al. 2011, Fuchs et al 2014) or casual-politicking (Gekker, see Chapter 20 in this volume). It will also describe the consequences on citizens that come with the shift from representational politics to participatory politics. Finally, it will turn to a discussion of the political 'game' itself, in order to ask, how radical is this gesture, how political is this new form of organization? Is it a game changer, or is it just the same old story, now in just a new, fancy light of participation?

\section{Organization and technology}

Organization has an odd and indirect relation to technology. As the American philosopher of technology Langdon Winner noted, there is a "technical constitution of society" $(1986,47)$. This is an interesting remark, as Winner did not write "technical dependence." Obviously, the means of our social organization cannot be directly deduced from technology or vice versa. However, Winner holds that they are fundamentally linked. In the era of industrialization, the link of technology and the political was widely debated via the means of production. In the era of digitalization on the other hand, we are about to shift our focus away from production and instead stress the matter of organization (Srnicek and Williams 2015; Virno 2006, 36; Baecker 2011). The Dutch philosopher of technology Peter-Paul Verbeek (2011) for example has explicitly shown how design always imposes a certain organization and with it a morality of things.

On an abstract level, the link between organization and technology reads as follows: everything that is organized has a pattern and a structure. To form a structure and hold on to a certain pattern, it requires communication, and communication is based on a technical element. A crowd or an individual is never simply there. Connections and distances are constantly communicated, negotiated, acknowledged, or denied: this is the work of a society, a work done with the help of a symbol, a paper form, or a poster, a meeting room, a telephone, a membership card, a digital platform, or a specific thing (Marres 2012). With the help of those communication tools, 
we form as multitudes (Virno 2004, 84), create assemblages (DeLanda 2006), or coordinate ourselves on platforms (Srnicek 2017).

If we apply this perspective to citizens, we can see the state as an "apparatus" (Althusser 1970) that produces a loose group, connected by the symbol of a passport. In Western societies, passports grant citizens certain responsibilities and rights, including, among others, the right that they may register to vote. This form of participatory power-the vote-has been the most important political act of the citizen; it represents his or her ability to control politics since in representative democracies we vote someone in and out of an office. However, if we compare the length of time it takes a citizen to cast a vote with the length of time a government is in power, the unbalance of this political division of labor becomes apparent: after the brief active moment of voting, we find that voters (i.e. 'us') are generally passive, while the politicians ('them') make the decisions. To overcome this division, participatory politics - getting the citizen to take a more active part via public campaigning or in local initiatives-has been a recurring theme. Especially in the 1960 s this turned into a strong participatory impulse, which was also expressed in art and culture (Debord 1967; Bishop 2006). Thus, we can say that in our most recent past, participation has been discussed as an emancipatory act. Not any more. Now that new forms of participation have evolved with digitalization, the positive rhetoric seems to have changed: Srnicek has denounced certain forms of participation as 'platform capitalism' (2017). Before him Schäfer (2009) already pointed out the misuse of participation as a replacement for market research. Since new digital forms of participatory politics continue to emerge in great scale, it is important to try to understand this more precisely: how does the increase in participatory politics and its transformation from an exception to a new norm affect the set-up of the political? Let us look at some examples from the recent history of digitalization.

\section{Forms of participation}

In 2009, the platform RaceOnline2012.org was created by Martha Lane Fox, co-founder of Lastminute.com. Its aim was to tackle the digital divide and bring millions of people, who had never been online, in touch with the internet. Bearing the gamification of politics in its name, the website made use of an interface that acquired details from people willing to help regarding on which weekday and time they or their seminar room or their computer would generally be available each week; or if they felt more comfortable 
with teaching a group or an individual person, making available a work place, a work tool, or working time. As we can see here, the interface was programmed to connect humans and "nonhumans" (Latour 1999, 174) as directly and detailed as possible.

Data.gov.uk is another example of early participatory politics. The UK government project, which started in 2010 and relaunched in 2018, enables developers to freely access non-personal data the state acquired for official purposes, from traffic sector data to crime statistics to the governments central accounting system. Initiated by the founder of the World Wide Web Sir Tim Berners-Lee and the computer professor Nigel Shadbolt, the website was launched in January 2010. A few years later, in 2013, some 9,00o data sets were available, and more than 2,500 developers had signed up to the project. The result of their experimental data use was the creation of many applications and websites, among them for example the 'Care Home Map,' which helps to evaluate the services of Care Homes for elderly relatives or friends, or 'Road Works,' which informs about planned government traffic works and helps to optimize logistics. With these projects, data.gov.uk became committed to the idea of government transparency and proclaimed it would open up government. It did this in parts, since most of us cannot handle this kind of raw data.

Here, digital participation introduces an interesting dilemma (see also Tkacz 2012). It can be summed up as follows: while data sets are of tremendous use to developers, they are of no use to the general public. Being able to use data depends on having digital skills, so making it available simultaneously triggers a digital divide. Paradoxically, digitalization introduces more participation, but it splinters the public —obviously the fragmentation of digitalization also affect publicness itself. To correct this, tools exist that lower the tech barriers and make app building and programming easier. These are ways to tackle this new digital exclusion, as the relapse to an equal but passive position is not an attractive alternative.

Finally, there is the interesting example of the Social Innovation Camp, a project that was founded in 2008 by, among others, the then global manager of Amnesty International Dan McQuillan, a scholar for creative and social computing at Goldsmiths University. The Social Innovation Camp brings digital solutions to social challenges by following the approach of what is known among coders as a 'hackday': by applying existing code to a new problem, programmers rapidly find creative solutions and are able to swiftly build a prototype. As digitalization allows new connections and a far more detailed administration of our world, this can be applied to real life, or as McQuillan puts it, we can "combine rapid prototyping with asset-based 
community development, using the ability of the Internet to aggregate and mash-up solutions to social issues" (2012). One outcome of this new approach is GoodGym.org, a project that mashes up participation with digital technology; instead of becoming a member at a gym, the service pairs runners with isolated and less mobile people in their area. Runners then jog to their house, deliver something nice, have a brief chat, and are on their way again.

\section{Participation and the citizen}

Let us now take a step back from the examples and focus on the political ethos these projects bring into play when addressing their issues. Firstly, we can notice that these issues do not have a political motive at all, whether in the traditional sense of politics as the activity of government, nor in the more recent radicalized conception of politics as 'post-politics.' This movement, represented by philosophers as different as Rancière, Badiou, Mouffe, and Žižek, aims for a new radical approach toward politics from the standpoint of equality, when finding politics proper reduced to social administration. Instead of compromise and consensus, they stress friction, debate, disagreement, and allowing the unheard voice to be accounted for (see Rancière 1999, 27ff). Both approaches, however, when compared to the 'gamification of politics,' do not seem to apply. Here, the social and political issues tackled have not moved back under the administrative wings of the government, but they also do not seem to be an issue in the post-political sense. All of them address urgent social problems but there is no friction or debate, there is no voice that makes itself heard, or a strong notion of inequality.

The problems present themselves as challenges that citizens can face and take part in, in case they are interested. Like in the setting of a game, political issues appear as simple fragments of a much bigger picture; there is also the opportunity with these game-like politics to take part, but there is no obligation. Instead of a political idea or ideology, there is a simple challenge; instead of tackling common problems in the world as a whole, we stick with solving a demarcated field or question or problem; instead of asking the citizen to believe in a political program, the issues at stake ask us to take part in finding a solution to a particular problem: join the club and play with us! Now Wittgenstein (1953) rightly observed that we may not be able to clearly define what a game is, but there are enough family resemblances between this new approach of tackling a social problem and 
the setting of a game: it is structured, a challenge, circumscribed in time and place, and although it is not fictitious it connects you with a different reality from your own. Do not let the elderly feel isolated. Help people who have no digital literacy. Open government and make it accessible for others. Fight for the survival of your planet. Save Lara Croft. The seamless gliding between both spheres makes it apparent that we can indeed claim the 'gamification of politics' when we define gamification as "the use of game design elements in non-game contexts" (Deterding et al. 2011, 10). If we explore the effect of this kind of gamification further, however, new questions arise: what are its consequences for politics? Does the gamification of politics not only change politics, but also change the approach of the state toward its citizens, and if so in what way?

As I have emphasized above, the social is not an obligation for everyone anymore, but a challenge that is optional, in which one can take part as if it were a game. Here, the gamification of politics changes the notion of the political in a very specific way, and the new notion of the political is triggered when the technical constitution of society (Winner 1986, 47) becomes visible. Clearly, the technical gesture (Latour 1999, 210) of digitalization is at work: fragmentation has dismantled the notion of 'everyone.' This leads to an urgent political question: What will happen to a state that is subjected to the logic of gamification when in the past it was a democratic apparatus set to ensure the values of justice, freedom, and equality for everyone? Let us ponder this question for a moment.

Replacing the war of 'all against all' while respecting the plurality of its people, the democratic state ideally provides its citizens with equal opportunities to live in freedom, so that everyone gets a fair chance to take part in society-Jacques Rancière has, among others, discussed equality as an essential and complex democratic value "on which any social order rests" (Rancière 1999, 16). The actual way that the social order is based on equality, however, changes in a digitalized society. Instead of facilitating just one equal opportunity for all (i.e. through voting), the state can now also offer a range of different possibilities to directly participate in its politics. Consequently, instead of 'a people' we have a plurality of different participants. This means while 'a people' can now be more active, they also find themselves divided into different groups, each one with different skills to 'play politics' at different levels — an interesting dilemma that needs to be discussed.

It becomes apparent that the rise of digital technology confronts the state with an interesting problem: to enable digital participation will necessarily mean the state is not the same for all. In a society fragmented into citizens 
with different skills, the idea of equality is without question still important but needs to be newly adjusted. While every one of its citizens should be able to browse the knowledge of the internet, not everyone necessarily needs to know how to code; everyone should, however, get an opportunity to learn this important and powerful task. Here, the state needs to struggle with the division of its people, for it should not deny its citizens the technical chance of taking a more active part in politics. Yet, the attractive option of opening government up has another flipside: when is a state enabling its citizens to participate politically and when is it simply outsourcing its responsibilities? This is a serious problem which this chapter will now turn to in order to discuss the potential of participatory politics as a game changer.

\section{Participatory politics as game changer?}

If we return for a moment to the beginning of this chapter, where we were introduced to Latour's proposition that "[f]orms of organization are inseparable from technical gestures" (1999, 210), we can now finally focus on the question of how inseparable these two phenomena are. Can a technical gesture initiate new forms of organization? Does it change the organization of our societies with regard to being socially truly revolutionary? Regarding technology, a revolutionary connotation has often been addressed. For a long time, philosophers have been especially fascinated by the deep impact technical change has had on society. Besides Marx, it was Walter Benjamin who most explicitly linked technology to a social revolution. When in Moscow in 1927, he wrote for example that "the revolutionary work of this hour is not conflict, not civil war, but canal construction, electrification, and factory building. The revolutionary nature of true technology is emphasized ever more clearly" (Benjamin 1927, 45). Langdon Winner also addresses technologies as a basic cause of social change $(1986,31)$, much like Corlann Gee Bush, who points out that technological change stimulates social change (1983). Let us now finally explore the ability of digital technology to change societies, as well as the participatory politics, and start with the obvious question: Does digital technology really change the way we organize our societies, or does it simply automatize it?

Analyzing digital technology, one can notice the potential of far more detailed organization than ever before, in which logistics is turned into an integral element of production (Thrift 2004, 182). Online interfaces automatically manage details and notify issues that, before the existence of algorithms, a human person had to ask, such as: When is this room free? 
When do you have some spare time? What skills do you have? When is a computer available? Or, when can this object be used? Again, it becomes obvious that digitalization connects and manages the world in far greater detail, and this will increasingly become the case with the further growth of the Internet of Things (Bunz and Meikle 2018). For instance, by using RFID chips not only humans, but also objects are able to answer inquiries (Hayles 2009) and this enables millions of new connections. This technical innovation takes the Internet of PCs to a next level since it makes objects digitally addressable.

The political potential of these new connections, as I have shown elsewhere in great detail (Bunz 2014, 109-115; Bunz and Meikle 2018), has fascinated media scientists, some even predict the emergence of a new media ontology (Kittler 2009). The human geographer Nigel Thrift, for example, writes about our new ability of tracking and tracing: "If things are showing up differently, we can do different things too, energetically opening up the new order of being" $(2004,188)$. McQuillan discusses this potential further as "hacking social reality": as the digital allows to transform pre-existing elements to evoke meanings not originally intended in the raw material, he argues that "we can prototype parts of a new society in the shell of the old" (2012). As Latour has indicated, the new digital technical gesture does not simply apply to automatize tasks, but truly opens up new forms of social organization since the change even goes further than what has existed. In effect, it interrupts existing mechanisms in their tracks: regarding organization digitalization is—again—skipping the intermediaries, or rather one intermediary, namely money.

If one analyzes the above-mentioned examples from the Social Innovation Camp to RaceOnline2012 more closely, it becomes apparent that they set the logic of money aside. Compared to websites of The Red Cross, Amnesty International, or Greenpeace, their homepages do (or did) not have a clearly visible donate button. Instead they stressed the notion of 'get involved.' This is symptomatic. Since they focus on connecting things and skills, humans and nonhumans directly, money is not at the center of their organization but just one means among others to reach their goal. And this is also the case with thepublicschool.org, Rynda.org, and many other examples leading to the conclusion that a new type of organization indeed has emerged in the digital era. Referring to 'non-governmental organizations' (NGOs) this new type can be categorized as 'non-money centered organizations' (NMCOs). These new possibilities, which have been described and supported by Trebor Scholz and Nathan Schneider (2017), introduce a potential for massive change. For example, before digitalization and its technical gesture of fragmentation 
had reached organization, the size of a budget clearly defined the size of an organization. Now this has changed. With the rise of NMCOs, the potential of playing a different game, one that might escape the logic of money, becomes apparent. While the new technical gesture gave rise to this new form of organization, it does not however dictate its political interpretation. Here the link of technical organization and social revolution, one that escapes the ruling logic of money, profit, and efficiency, comes to an end. Technology and organization are inseparable, but their political interpretation is not. Or, to put it differently, the fact that technology enables new forms of organization does not mean the direction of change is automatically set for a revolution. Participatory politics are pushed further by the technical gesture of digitalization so they can be a game changer, but they can also be used as a means to outsource social responsibilities from the state to its citizens. For example, 'Do It - Volunteering made easy' is a website from the charity YouthNet supported by the UK Cabinet Office which enables citizens to find voluntary work in their area. After the public sector job cuts in the UK heavily affected social services - the Office for Budget Responsibilities report showed that by the second quarter of 2011 General Government Employment fell by 80,000 - there were obviously many opportunities to volunteer. This work was often being done by professional social workers who had at one time been employed by the state. In April 2018, a search limited to a five-mile area in East London displayed 1475 volunteer opportunities, including helping sixteen- to nineteen-year-olds in their local school or college, being the weekend receptionist in a hospital, or joining clean-ups in the local area. Here, participatory technology does not innovate, but simply helps to replace a retracting state. Participatory technology is simply being used to keep on reproducing the same social situations instead of creating new ones that may unlock a new becoming.

\section{Conclusion}

While exploring Latour's proposition in the era of digitalization and looking into new forms of organization like participatory politics, it became apparent that his statement is still relevant: "forms of organization are inseparable from technical gestures." The fact that technology is inseparable from organization influences but does not determine politics. In other words, digital technology opens up new forms of organization, but the question of the political remains. When do we play a new game? And when do we just change the rules in order to replay the old game on a new board? 


\section{References}

Althusser, L. 1970. Idéologie et appareils idéologiques d'État (Notes pour une recherche). La Pensée 151.

Baecker, D. 2011. Technik und Entscheidung. In Die technologische Bedingung. Beiträge zur Beschreibung der technischen Welt, ed. E. Hörl, 179-192. Berlin: Suhrkamp.

Benjamin, W. 1927. Moscow. In Selected writings volume 1, 1927-1934. Trans. R. Livingstone and others, 22-46. Cambridge, MA: Harvard University Press. Bishop, C. 2006. Participation. Cambridge, MA: The MIT Press.

Bruns, A., G. Enli, E. Skogerbo, A. O. Larsson, and C. Christensen, eds. 2015. The Routledge companion to social media and politics. New York: Routledge.

Bunz, M. 2014. The silent revolution: How digitalization transforms knowledge, work, journalism, and politics without making too much noise. Houndmills: Palgrave Macmillan.

Bunz, M., and G. Meikle. 2018. The internet ofthings. Malden, MA: Polity Press.

Bush, C. G. 1983. Women and the assessment of technology: To think, to be; to unthink, to free. In Machina ex dea: Feminist perspectives on technology, ed. J. Rothschild, 151-170. New York: Pergamon Press.

Castells, M. 1996. The rise of the network society. The information age: Economy, society and culture vol. I. Oxford: Blackwell.

Debord, G. 1967. Society of the spectacle. New York: Zone Books.

DeLanda, M. 2006. A new philosophy of society: Assemblage theory and social complexity. London, New York: Continuum.

Deterding, S., D. Dixon, R. Khaled, and L. Nacke. 2011. From game design elements to gamefulness: Defining "gamification". In Proceedings of the 15th international academic MindTrek conference: Envisioning future media environments, Tampere, September 28-30, 2011, 9-15. New York: ACM.

Fuchs, M., S. Fizek, P. Ruffino, and N. Schrape. 2014. Rethinking gamification. Lüneburg: meson press.

Galloway, A. 2004. Protocol: How control exists after decentralization. Cambridge, MA: The MIT Press.

Hayles, K. 2009. RFID: Human agency and meaning in information-intensive environments. Theory, Culture \& Society 26 (2-3): 47-72.

Kittler, F. 2009. Towards an ontology of media. Theory, Culture \& Society $26(2-3): 23-31$.

Latour, B. 1999. Pandora's hope: Essays on the reality of science studies. Cambridge, MA: Harvard University Press.

Lovink, G. 2012. Networks without a cause. Malden, MA: Polity Press. 
Marres, N. 2012. Material participation: Technology, the environment and everyday publics. London: Springer.

McQuillan, D. 2012. Could prototyping be the new policy? The Guardian. http://www.guardian.co.uk/culture-professionals-network/cultureprofessionals-blog/2012/may/28/prototyping-replaces-policy-arts-culture. Rancière, J. 1999. Disagreement: Politics and philosophy. Trans. J. Rose. Minneapolis, MN: University of Minnesota Press.

Schäfer, M. T. 2009. Participation inside? User activities between design and appropriation. In Digital material: Tracing new media in everyday life and technology, eds. M. van den Boomen, S. Lammes, A. Lehmann, J. Raessens, and M. T. Schäfer, 147-158. Amsterdam: Amsterdam University Press.

Scholz, T., and N. Schneider, eds. 2017. Ours to hack and to own: The rise of platform cooperativism, a new vision for the future of work and a fairer internet. New York: OR Books.

Srnicek, N. 2017. Platform capitalism. Malden, MA: Polity Press.

Srnicek, N., and A. Williams. 2015. Inventing the future: Postcapitalism and a world without work. London: Verso Books.

Thrift, N. 2004. Remembering the technological unconscious by foregrounding knowledges of position. Environment and Planning D: Society and Space 22 (1): 175-190.

Tkacz, N. 2012. From open source to open government: A critique of open politics. Ephemera, Theory and Politics in Organization 12 (4): 386-405.

Verbeek, P. 2011. Moralizing technology: Understanding and designing the morality of things. Chicago, IL: University of Chicago Press.

Virno, P. 2004. A grammar of the multitude. Boston, MA: The MIT Press.

-. 2006. Reading Gilbert Simondon: Transindividuality, technical activity and reification. Radical Philosophy 136:34-43.

Winner, L. 1986. The whale and the reactor: A search for limits in an age of high technology. Chicago, IL: University of Chicago Press.

Wittgenstein, L. 1953. Philosophical investigations. Hoboken, NJ: Blackwell Publishing.

\section{About the author}

Mercedes Bunz is Senior Lecturer at the Communications and Media Research Institute, University of Westminster. Her research focuses on digital technology and how it affects society, especially regarding knowledge and work. Her publications include The internet of things (2018), written together with Professor Graham Meikle, in which she explored new skills that things 
have, such as 'seeing' and 'speaking' gathered through artificial intelligence. She also wrote The silent revolution: How digitalization transforms knowledge, work, journalism, and politics without making too much noise (Palgrave 2014), and co-edited Terra critica: Symptoms of our planetary condition (Meson Press 2017). 